\title{
Post-Traumatic Subdural Hygroma: A One Year Follow up Case Report and Literature Review
}

\author{
Esteban Ortiz-Prado ${ }^{1,2}$, Tamara Acosta Castillo ${ }^{3}$, Mauricio Olmedo López ${ }^{3}$, \\ Mario A. Rubio ${ }^{4,5}$ \& Luis E. Bermeo ${ }^{1}$ \\ ${ }^{1}$ Faculty of Medicine, Universidad de las Americas, Quito, Ecuador \\ ${ }^{2}$ Department of Medicine and Center for Global Health and Translational Science, State University of New York, \\ Upstate Medical University, Syracuse, NY, USA \\ ${ }^{3}$ Faculty of Medicine, Faculty of Medicine, Universidad Central del Ecuador, Quito, Ecuador \\ ${ }^{4}$ Hospital Regional, Mexico, DF \\ ${ }^{5}$ Instituto Nacional de Pediatría, Mexico, DF \\ Correspondence: Esteban Ortiz-Prado, Universidad de las Américas, Calle de los Colimes, Av. De los Granados, \\ Quito 170137, Ecuador. E-mail: e.ortizprado@gmail.com
}

Received: March 19, 2016 Accepted: April 2, 2016 Online Published: April 29, 2016

doi:10.5539/gjhs.v8n12p239 URL: http://dx.doi.org/10.5539/gjhs.v8n12p239

\begin{abstract}
Post-traumatic subdural hygroma it is an intracranial lesion, commonly misdiagnosed due to its unclear symptomatology and slow progression. Defined as the presence of cerebral spinal fluid in between the arachnoid and the duramater layers; causing a variety of symptomatology that usually depend on the amount of fluid within this space (subdural). Post traumatic subdural hygroma it's observed in 5-20\% of all blunt head injuries, although its diagnosis it's usually rare among emergency departments. Prognosis is usually good due to the absence of severe complications and its spontaneous resolution in mostly of the cases. We present a 26-year-old male patient, with history of high impact blunt trauma, presenting ocular refractive changes and headache. After CT scan evaluation and BOLD-MRI confirmation, a bilateral fronto-parietal subdural hygroma was confirmed.
\end{abstract}

Keywords: subdural hygroma, subdural hematoma, head, arachnoids cyst, subdural space, BOLD MRI

\section{Introduction}

Traumatic brain injuries (TBI) are a public health concern worldwide (Roozenbeek, Maas, \& Menon, 2013). The incidence of TBI have raised in developed and developing countries, showing increasingly higher emergency department (ED) visits in the last 10 years (Marin et al., 2014; Roozenbeek, Maas, \& Menon, 2013), accounting for a worldwide incidence between 100 to 550 per 100,000 people (Wu et al., 2008; Andersson et al., 2003; Belanger et al., 2007). In the United States, TBI emergency room visits increased 8 folds in less than 10 years (Marin et al., 2014). Mild brain injuries account for up to $75 \%$ to $95 \%$ of head traumas worldwide, however, severe brain injuries are correlated with worst prognosis and higher mortality (Bryant et al., 2010; Roozenbeek et al., 2011; Badri et al., 2012; Baum et al., n. d.; Røe et al., 2015).

TBI is often seen in younger males that were involved in car or motorcycle accidents as well as in high impact sports lesions (Ansari-Moghaddam et al., 2013; Monsef Kasmaei et al., 2015; Ling, Hardy, \& Zetterberg, 2015). This type of trauma is one of the leading causes of disability and death among patients under 25 years, especially in developing countries (Ansari-Moghaddam et al., 2013; Monsef Kasmaei et al., 2015; Carney et al., 2012).

High impact head traumas can cause open or closed injuries, skull fractures, epidural, subdural or intracranial hematomas, or less severe alterations such as concussions or post traumatic hygromas (McCrory et al., 2013; Ling, Hardy, \& Zetterberg, 2015; Røe et al., 2015). The severity of the trauma will determine the treatment to be implemented, the neurological sequelae and the final prognosis (Roozenbeek et al., 2011; Baum et al., n.d.). Depending on the severity of the trauma, the clinical presentation and the resources available, the majority of patients require at least one imaging test, often, a Computed Tomography (CT) or a Magnetic Resonance (MRI) in order to confirm diagnosis and implement proper treatment (Lee \& Newberg, 2005; Belanger et al., 2007; Coles, 2007; Schneier et al., 2006). 
Although CT scan or Brain MRI is often used to detect brain injury, not every lesion has detectable radiological signs, making diagnosis difficult in some scenarios (Belanger et al., 2007).

Post Traumatic Subdural hygroma (PTSH) it's a posttraumatic complication that may coexist with epidural or subdural hematomas, being this neurological lesion often misdiagnosed and many times overlooked (Rambarki \& Rajesh, 2014; Huh et al., 2006; Miranda et al., 2004). PTSH are often referred as chronic subdural hematomas, hydromas, Meningitis serosa traumatica, subdural effusion or chronic hygromas (Wittschieber et al., 2015; Oka et al., 1972; Ki et al., 2015; Lee, 1998). This lesion usually evolves silently or with mild general symptoms and commonly resolves by itself without any treatment (Mack, Squier, \& Eastman, 2009; Lee, 1998; Zanini et al., 2008).

PTSH are usually wrongly considered chronic subdural hematomas, especially after head trauma or Cerebrospinal fluid (CSF) accumulation or effusion (Wittschieber et al., 2015; Zanini et al., 2008). For these cases, the physiopathological mechanisms involved are the traumatically induced tears in the arachnoid membrane, rupture of a congenital arachnoid cyst or CSF leakage due to post inflammatory formation of neomembranes and new vessels (neovascularization) (Rajesh, Bramhaprasad, \& Purohit, 2012; Kusuno et al., 1984; Stone et al., 1981).

Diagnosis of PTSH its radiological; a positive CT or MRI sign accompanied by relevant clinical presentation are needed before ensuring an accurate diagnosis, nevertheless, just $13 \%$ of patients with mild traumatic brain injury who underwent CT scan imaging exhibit radiological signs of post-traumatic subdural hygroma (Todorow \& Happe, 1981).

Evolution and prognosis in PTSH patients it's usually favorable, being spontaneous, non surgical resolution the final treatment for most uncomplicated cases (Rajesh, Bramhaprasad, \& Purohit, 2012; Wittschieber et al., 2015; Ki et al., 2015).

\section{Case Report}

A 26 years old male, with 15 days' history of high impact head trauma, was seen in a tertiary clinical center in Quito, Ecuador after presenting acute intense headache and blurry vision. His relatives inform that approximately 15 days ago he fell from his bicycle while using a "fullface" helmet that could not prevent him to having one generalized tonic-clonic seizure lasting at least 1 minute, accompanied with transitory altered state of consciousness, condition that not received any medical attention.

At arrival his vital signs were normal, AT 120/70mmHg, HR: 90', RR: 20' SO2: 98\% and Glasgow Coma Scale $15 / 15$. He arrived conscious, oriented in time, place, his pupils are isochoric with normal-reactivity to light and accommodation, no signs of focal lesion or any cranial nerve affection. His only complain it's a severe holocranial headache that is exacerbated by coughing, sneezing and Valsalva maneuvers. Additionally, a very intense discomfort was reported with minimal head movements, especially when the patient lies in prone position affecting visual acuity temporally.

The patien was sent to another hospital to obtain a normal no contrasted CT scan. When results arrived, a bilateral fronto-parietal hypodense accumulation, suggestive of some sort of subdural effusion was observed. There is no sign of intraparenchymal lesion or deviation of the medial line (Figure 1) and symptomatology did not correlated with more severe subdural hematomas. 


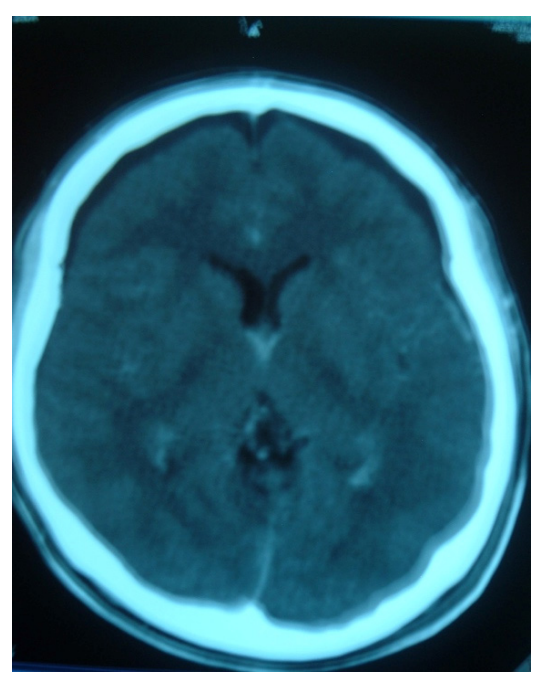

Figure 1. CT scan performed 30 days after injury, where the presence of hypodense accumulation is evident in the subdural space, bilateral fronto-parietal level

The initial diagnosis was acute isodense subdural hematoma vs. a chronic subdural hygroma. After reviewing the images with the radiology team and due to the relatively mild clinical presentation, a possible chronic subdural hematoma was discarded. It was decided to treat the patient conservatively with Ibuprofen $800 \mathrm{mg}$ TID, Paracetamol 500mg QD and Valproic Acid 500mg BID for 10 days.

After two weeks, the patient reported significant improvement, although mild visual disturbances and some unspecific discomfort associated with head movements were still present.

One year after the accident, during the follow up appointment, a total recovery was confirmed with the patient. No neurological signs or symptomatology was found.

As part of a medical investigation, a Magnetic Resonance Image (MRI) and functional BOLD MRI (Blood oxygen level Dependent MRI) were performed in order to confirm the absence of any subdural effusion (Figure 2).

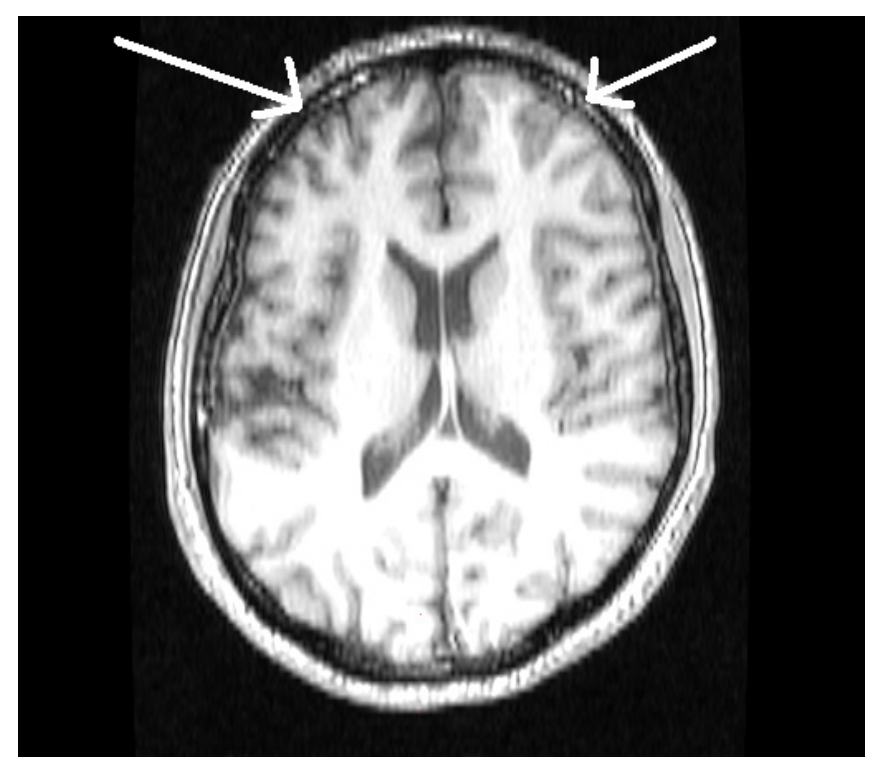

Figure 2. MRI after one-year trauma, where the presence of radiological signs consistent with fibrosis are evident, it differentiates form chronic subdural hematoma which is hypodense 
The anatomical MRI showed the presence of mild subdural fibrosis, at the bilateral fronto-parietal level. On the other hand, the functional BOLD MRI showed an image compatible with neovascularization in the same areas where the subdural effusion was seen, suggesting the diagnosis of post-traumatic subdural hygroma from an inflammatory etiology (Figure 3).

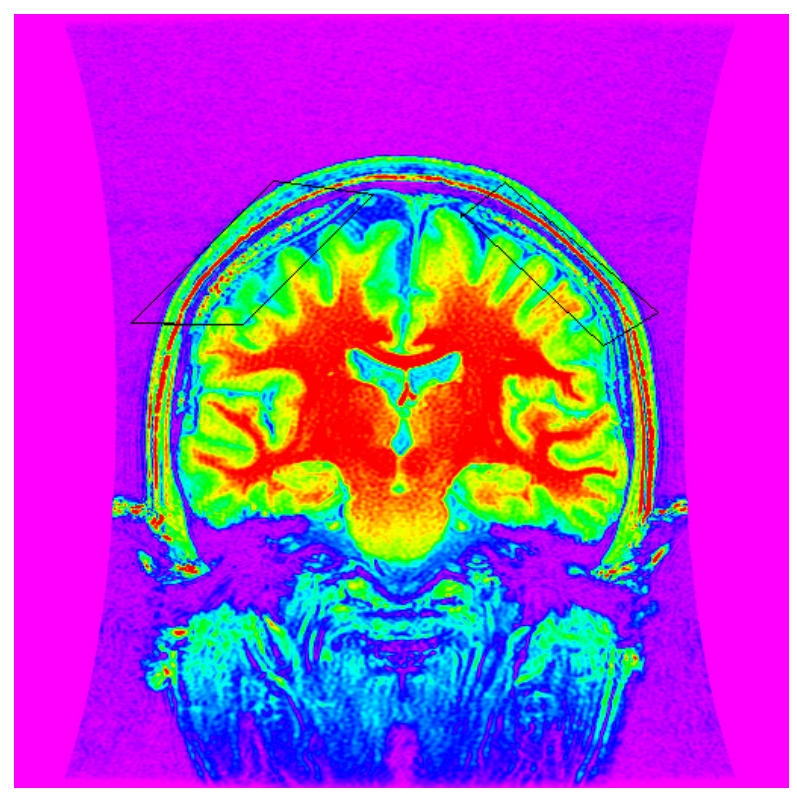

Figure 3. BOLD MRI imaging showing hyperintensity activity within the subdural space

\section{Discussion}

A subdural hygroma (SH) is defined as acute or chronic Cerebrospinal fluid accumulation in the subdural space, which is actually a virtual space between the arachnoid and subdural membranes (Zanini et al., 2008).

This condition represents up to $12 \%$ of all intracranial posttraumatic masses (Herold et al., 2004; Lee et al., 1996) and up to $20 \%$ of all the blunt closed head injuries (Lee, Bae, Bae, et al., 2000; Lee, 2004). It is relatively more common in patients between 10-50 years of age as a late complication of head trauma and since mostly of them are silent and resolved spontaneously, an important number might not be diagnosed (French et al., 1978; Lee, 1998; Rambarki \& Rajesh, 2014).

This type of lesion is usually associated with cerebral atrophy, contusions, subdural and epidural hematomas or in mostly of the case, posts operatory complications (McCluney et al., 1992; Zanini et al., 2008; French et al., 1978; Park et al., 2015; Sun, Chang, \& Hsieh, 2014; Wad et al., 2013). Prognosis it's usually good, although some reports suggest that in some cases, up to $28 \%$ of patients die, condition directly related with the severity of the primary head trauma (Wittschieber et al., 2015; Rambarki \& Rajesh, 2014; Stone et al., 1981; Koizumi et al., 1981).

As stated before, some studies show that normal CT scans can not always detect this type of lesion, however, when detected, the most common presentation is a bilateral subdural effusion. This effusion is located mainly within the frontoparietal lobules representing more than $77 \%$ of the cases, followed by the posterior fossa with $2.5 \%$ and very rarely within the medullar subdural space(Lee, Bae, Yoon, et al., 2000; Kabir, Jennings, \& Makris, 2004; Traumatic Epidural Haematoma of the Posterior Fossa in Childhood: 16 New Cases and a Review of the Literature.-PubMed-NCBI, n. d.).

Regardless the location, subdural effusions are the result of traumatic (mechanic) and non-traumatic forces, being the first one the main etiological cause (Zanini et al., 2008). Some of the most common post traumatic reasons are those presented in patients who have undergone craniotomies, surgical resection of aneurysms, drainage of hematomas or removal of intracranial tumors (Alotaibi et al., 2014; Park et al., 2015; Van Den Berg et al., 2002). Obstetric trauma is another common cause of SH among infants, followed by head trauma, specially the shaken baby syndrome (Ebner et al., 2015; Wittschieber et al., 2015; Nixon \& Soares, 2016). 
Although etiology it's well known, pathogenesis of this condition is not well understood. Some theories have gained more support and include: The formation of a one-way valve allowing the passage of CSF into the subdural space, caused by a traumatic tear of the arachnoidal mater or due to the rupture of an existing arachnoids cyst (Kusuno et al., 1984; Rajesh, Bramhaprasad, \& Purohit, 2012; Pillai et al., 2009). An underlying parenchymal or vascular disorder that causes a passive effusion into the subdural space (Stone et al., 1981; Maddalozzo et al., 1999; Wittschieber et al., 2015) and new formation of subdural vascularized neomembranes accompanied by increased permeability of CSF in the arachnoids membrane, which might be linked with the meningeal barrier permeability or by increasing the transmembrane pressure gradient (Thompson, Lee, \& MacIntosh, 2015; Bora et al., 2015; Strahle et al., 2015).

On the other hand, the most common non-traumatic subdural hygroma in the elderly group is largely due to brain atrophy (Tanaka \& Ohno, 2013). And many times triggered as a result of uncontrolled administration of hypertonic agents, hypernatremia, marked dehydration, long-term coughing or sneezing, recurrent or Valsalva maneuvers (Dierckx et al., 1988).

Subdural hygroma have been also related to infectious disease such as tuberculosis and some rare chromosomal syndromes such as Menkes disease, which is a rare disorder X-linked, characterized by alteration of copper metabolism (Jain et al., 2014; Cho et al., 2005; Fisher \& Hiller 1994).

In order of frequency, the most common symptoms are: slight changes in the state of consciousness, holocranean headache which is exacerbated by movement, coughing, nausea, vomiting, they can also occur vision disorders such as diplopia or slowing of accommodation; and rarely, coma and death (Alotaibi et al., 2014; Thompson, Lee, \& MacIntosh, 2015; Park et al., 2015).

Cisternography, angiography and surgical drainage were used as a diagnostic test, but currently the CT and MRI are the main diagnostic methods, the use of contrast is not recommended because there is no significant evidence of its diagnostic utility (Wittschieber et al., 2015; Duhem et al., 2006; Lee \& Newberg, 2005; Nixon \& Soares, 2016).

When looking to diagnose hygromas, CT scan is very useful, although some intracranial injuries should be taken into account before ruling in hygromas (Alotaibi et al., 2014). The most common differential diagnosis is made with acute subdural isodense hematomas (Huh et al., 2006; Tanaka \& Ohno, 2013). To the unexperienced eye, hematomas and hygromas might look alike, being the Housefields units ranging from +10 and +16 , an important tool to diagnose PRSH in the presence of cerebral effusions (Mori \& Maeda, 2000).

After diagnosis, conservative treatment is the the primary election and its usually aimed at reduce symptomatology (Kumar et al., 2010). In large hygromas, when mass effect and compression is diagnosed, surgery will provide relieve (Thompson, Lee, \& MacIntosh, 2015; Park et al., 2015).

\section{Conclusions}

Subdural hygromas are a relatively common but under diagnosed intracranial lesion. Etiology is not totally understood, being head trauma the most important factor related with its origin, many times its diagnosis is confused with subdural isodense hematomas.

Most cases are not detected due to poor and unspecific symptomatology; thus a suspicious eye is needed when obtaining a suspicious CT scan with unspecific symptomatology. Although most patients will present headache and diverse symptomatology, conservative treatment works well in the majority of cases.

Following up a case like this opens the possibility to understand the behavior of this pathology. On the other hand, this is the first time that a BOLD MRI was used to confirm the presence of subdural vascular activity related with previous effusion.

We recommend that all the patients with history of head trauma and unclear clinical presentation should be seen by a neurologist and a neurosurgeon to conform diagnosis and to decide the appropriate treatment.

\section{Competing Interests Statement}

The authors declare that there is no conflict of interests regarding the publication of this paper.

\section{References}

Alotaibi, N. M., Christopher, D. W., Germans, M. R., \& Macdonald, R. L. (2014). Spontaneous Subdural Fluid Collection Following Aneurysmal Subarachnoid Hemorrhage: Subdural Hygroma or External Hydrocephalus? Neurocritical Care, 21(2), 312-315. http://dx.doi.org/10.1007/s12028-014-0017-5

Andersson, E. H., Björklund, R., Emanuelson, I., \& Stålhammar, D. (2003). Epidemiology of Traumatic Brain 
Injury: A Population Based Study in Western Sweden. Acta Neurologica Scandinavica, 107(4), 256-259. http://dx.doi.org/10.1034/j.1600-0404.2003.00112.x

Ansari-Moghaddam, Alireza, Abdolvahab Baghbanian, Mitra Dogoonchi, et al.

Badri, S., Chen, J., Barber, J., Temkin, N. R., Dikmen, S. S., Chesnut, R. M., ... Treggiari, M. M. (2012). Mortality and Long-Term Functional Outcome Associated with Intracranial Pressure after Traumatic Brain Injury. Intensive Care Medicine, 38(11), 1800-1809. http://dx.doi.org/10.1007/s00134-012-2655-4

Belanger, H. G., Rodney, D., Vanderploeg, G. C., \& Deborah, L. W. (2007). Recent Neuroimaging Techniques in Mild Traumatic Brain Injury. The Journal of Neuropsychiatry and Clinical Neurosciences, 19(1), 5-20. http://dx.doi.org/10.1176/jnp.2007.19.1.5

Bora, A., Yokuş, A., Batur, A., Bulut, M. D., Yavuz, A., Gülşen, İ., ... Arslan, M. (2015). Spontaneous Rupture of the Middle Fossa Arachnoid Cyst into the Subdural Space: Case Report. Polish Journal of Radiology, 80, 324. http://dx.doi.org/10.12659/ PJR.893928

Bryant, R. A., O'Donnell, M. L., Creamer, M., McFarlane, A. C., Clark, C. R., \& Silove, D. (2010). The Psychiatric Sequelae of Traumatic Injury. American Journal of Psychiatry, 167(3), 312-320. http://dx.doi.org/10.1176/appi.ajp.2009.09050617

Carney, N., Lujan, S., Dikmen, S., Temkin, N., Petroni, G., Pridgeon, J., ... Chesnut, R. (2012). Intracranial Pressure Monitoring in Severe Traumatic Brain Injury in Latin America: Process and Methods for a Multi-Center Randomized Controlled Trial. Journal of Neurotrauma, 29(11), 2022-2029. http://dx.doi.org/10.1089/neu.2011.2019

Cho, B. C., Kang, S.-M., Lee, S. C., Moon, J. G., Lee, D. H., \& Lim, S. H. (2005). Primary Idiopathic Chylopericardium Associated with Cervicomediastinal Cystic Hygroma. Yonsei Medical Journal, 46(3), 439-444. http://dx.doi.org/10.3349/ymj.2005.46.3.439

Coles, J. P. (2007). Imaging after Brain Injury. British Journal of Anaesthesia, 99(1), 49-60. http://dx.doi.org/10.1093/bja/aem141

Dierckx, R. A., Bruyland, M., Nuyens, Z., et al. (1988). Non-Traumatic Subdural Hygroma. Acta Neurologica Belgica, 89(5), 352-357.

Duhem, R., Vinchon, M., Tonnelle, V., Soto-Ares, G., \& Leclerc, X. (2006). Main temporal aspects of the MRI signal of subdural hematomas and practical contribution to dating head injury. Neuro-Chirurgie, 52(2-3 Pt 1), 93-104. http://dx.doi.org/10.1016/S0028-3770(06)71203-6

Ebner, L., Christe, A., El-Koussy, M., Steinlin, M., Stranzinger, E., Thali, M., \& Flach, P. M. (2015). Battered Child: Cranial Imaging Findings in a Distinct Case of Non-Accidental Injury. Journal of Forensic Radiology and Imaging, 3(2), 137-138. http://dx.doi.org/10.1016/j.jofri.2014.11.005

Fisher, D., \& Hiller, N. (1994). Case Report: Giant Tuberculous Cystic Lymphangioma of Posterior Mediastinum, Retroperitoneum and Groin. Clinical Radiology, 49(3), 215-216. http://dx.doi.org/10.1016/S0009-9260(05) $81782-9$

French, B. N., Cobb, C. A., Corkill, G., \& Youmans, J. R. (1978). Delayed Evolution of Posttraumatic Subdural Hygroma. Surgical Neurology, 9(3), 145-148.

Herold, T. J. S., Taylor, S., Abbrescia, K., \& Hunter, C. (2004). Post-Traumatic Subdural Hygroma: Case Report. The Journal of Emergency Medicine, 27(4), 361-366. http://dx.doi.org/10.1016/j.jemermed.2004.03.018

Huh, P.-W., Yoo, D.-S., Cho, K.-S., Park, C.-K., Kang, S.-G., Park, Y.-S., ... Kim, M.-C. (2006). Diagnostic Method for Differentiating External Hydrocephalus from Simple Subdural Hygroma. Journal of Neurosurgery, 105(1), 65-70. http://dx.doi.org/10.3171/jns.2006.105.1.65

Jain, Puneet, Lakshminarayanan Kannan, Biswaroop Chakrabarty, et al. 2014 Menkes Disease-An Important Cause of Early Onset Refractory Seizures. Journal of Pediatric Neurosciences, 9(1), 11-16. http://dx.doi.org/10.4103/1817-1745.131471

Kabir, S. M. R., Jennings, S. J., \& Makris, D. (2004). Posterior Fossa Subdural Hygroma with Supratentorial Chronic Subdural Haematoma. British Journal of Neurosurgery, 18(3), 297-300. http://dx.doi.org/10.1080 /02688690410001732797

Kasmaei, M., Vahid, P. A., Zohrevandi, B., \& Raouf, M. T. (2015). An Epidemiologic Study of Traumatic Brain Injuries in Emergency Department. Emergency, 3(4), 141-145. 
Ki, H. J., Lee, H.-J., Lee, H.-J., Yi, J.-S., Yang, J.-H., \& Lee, I.-W. (2015). The Risk Factors for Hydrocephalus and Subdural Hygroma after Decompressive Craniectomy in Head Injured Patients. Journal of Korean Neurosurgical Society, 58(3), 254-261. http://dx.doi.org/10.3340/jkns.2015.58.3.254

Koizumi, H., Fukamachi, A., Wakao, T., Tasaki, T., Nagaseki, Y., \& Yanai, Y. (1981). Traumatic subdural hygromas in adults--on the possibility of development of chronic subdural hematoma (author's transl). Neurologia Medico-Chirurgica, 21(4), 397-406. http://dx.doi.org/10.2176/nmc.21.397

Kumar, N., Kohli, M., Pandey, S., \& Tulsi, S. P. S. (2010). Cystic Hygroma. National Journal of Maxillofacial Surgery, 1(1), 81. http://dx.doi.org/10.4103/0975-5950.69152

Kusuno, K., Yoshida, Y., Takahashi, A., \& Ishii, S. (19840. Chronic subdural hygroma caused by rupture of arachnoid cyst. As a probable course of chronic subdural hematoma--case report. Neurologia Medico-Chirurgica, 24(5), 349-354. http://dx.doi.org/10.2176/nmc.24.349

Lee, B., \& Newberg, A. (2005). Neuroimaging in Traumatic Brain Imaging. NeuroRx, 2(2), 372-383. http://dx.doi.org/10.1602/neurorx.2.2.372

Lee, K. S. (1998). The Pathogenesis and Clinical Significance of Traumatic Subdural Hygroma. Brain Injury, 12(7), 595-603. http://dx.doi.org/10.1080/026990598122359

Lee, K. S., Bae, W. K., Bae, H. G., \& Yun, I. G. (2000). The Fate of Traumatic Subdural Hygroma in Serial Computed Tomographic Scans. Journal of Korean Medical Science, 15(5), 560-568. http://dx.doi.org/ 10.3346/jkms.2000.15.5.560

Lee, K. S., Bae, W. K., Yoon, S. M., Bae, H. G., \& Yun, I. G. (2000) Location of the Traumatic Subdural Hygroma: Role of Gravity and Cranial Morphology. Brain Injury, 14(4), 355-361. http://dx.doi.org/10. 1080/026990500120646

Lee, K. S., Doh, J. W., Bae, H. G., \& Yun, I. G. (1996). Relations among Traumatic Subdural Lesions. Journal of Korean Medical Science, 11(1), 55-63. http://dx.doi.org/10.3346/jkms.1996.11.1.55

Lee, K.-S. (2004). Natural History of Chronic Subdural Haematoma. Brain Injury, 18(4), 351-358. http://dx.doi.org/10.1080/02699050310001645801

Mack, J., Squier, W., \& Eastman, J. T. (2009). Anatomy and Development of the Meninges: Implications for Subdural Collections and CSF Circulation. Pediatric Radiology, 39(3), 200-210. http://dx.doi.org/10. 1007/s00247-008-1084-6

Maddalozzo, J., Hughes, A., Huang, L. J., Mu, Y., Ludemann, J., \& Crawford, S. (1999). High Angiogenic Activity in Cells Isolated from Cystic Hygroma: Role of bFGF. Archives of Otolaryngology-Head \& Neck Surgerym 125(1), 45-48. http://dx.doi.org/10.1001/archotol.125.1.45

Marin, J. R., Weaver, M. D., Yealy, D. M., \& Mannix, R. C. (2014). TRends in Visits for Traumatic Brain Injury to Emergency Departments in the United States. JAMA, 311(18), 1917-1919. http://dx.doi.org/10.1001/jama. 2014.3979

McCluney, K. W., Yeakley, J. W., Fenstermacher, M. J., Baird, S. H., \& Bonmati, C. M. (1992). Subdural Hygroma versus Atrophy on MR Brain Scans: "The Cortical Vein Sign". American Journal of Neuroradiology, 13(5), 1335-1339.

McCrory, P., Meeuwisse, W. H., Aubry, M., Cantu, B., Dvořák, J., Echemendia, R. J., ... Turner, M. (2013) Consensus Statement on Concussion in Sport: The 4th International Conference on Concussion in Sport Held in Zurich, November 2012. British Journal of Sports Medicine, 47(5), 250-258. http://dx.doi.org/10.1136/bjsports-2013-092313

Miranda, P., Lobato, R. D., Rivas, J. J., Alén, J. F., \& Lagares, A. (2004). Postraumatic subdural collections: Case report and review of the literature. Neurocirugia (Asturias, Spain), 15(1), 67-71. http://dx.doi.org/ 10.1016/S1130-1473(04)70503-5

Mori, K., \& Maeda, M. (2000). Delayed Magnetic Resonance Imaging with Gd-DTPA Differentiates Subdural Hygroma and Subdural Effusion. Surgical Neurology, 53(4), 303-311. http://dx.doi.org/10.1016/S00903019(00)00199-3

Nixon, J. N., \& Soares, B. P. (2016). Imaging of Abusive Head Trauma: A Review and Update. Current Radiology Reports, 4(2), 1-18. http://dx.doi.org/10.1007/s40134-015-0136-6

Oka, H., Motomochi, M., Suzuki, Y., \& Ando, K. (1972). Subdural Hygroma after Head Injury. A Review of 26 
Cases. Acta Neurochirurgica, 26(4), 265-273. http://dx.doi.org/10.1007/BF01407072

Park, J., Cho, J.-H., Goh, D.-H., et al. (2015). Postoperative Subdural Hygroma and Chronic Subdural Hematoma after Unruptured Aneurysm Surgery: Age, Sex, and Aneurysm Location as Independent Risk Factors. Journal of Neurosurgery, 1-8.

Pillai, P., Menon, S. K., Manjooran, R. P., Kariyattil, R., Pillai, A. B., \& Panikar, D. (2009). Temporal Fossa Arachnoid Cyst Presenting with Bilateral Subdural Hematoma Following Trauma: Two Case Reports. Journal of Medical Case Reports, 3(1), 53. http://dx.doi.org/10.1186/1752-1947-3-53

Rajesh, A., Bramhaprasad, V., \& Purohit, A. K. (2012). Traumatic Rupture of Arachnoid Cyst with Subdural Hygroma. Journal of Pediatric Neurosciences, 7(1), 33-35. http://dx.doi.org/10.4103/1817-1745.97620

Rambarki, O., \& Rajesh, A. (2014). Dreaded Complications of Mistaken Identity-Hygroma vs Effusion Following Decompressive Craniotomy. Journal of Neurosciences in Rural Practice, 5(3), 305-307. http://dx.doi.org/10.4103/0976-3147.133623

Røe, C., Skandsen, T., Manskow, U., Ader, T., \& Anke, A. (2015). Mortality and One-Year Functional Outcome in Elderly and Very Old Patients with Severe Traumatic Brain Injuries: Observed and Predicted. Behavioural Neurology, 845491. http://dx.doi.org/10.1155/2015/845491

Roozenbeek, B., Chiu, Y.-L., Lingsma, H. F., Gerber, L. M., Steyerberg, E. W., Ghajar, J., \& Maas, A. I. R. (2011). Predicting 14-Day Mortality after Severe Traumatic Brain Injury: Application of the IMPACT Models in the Brain Trauma Foundation TBI-Trac ${ }^{\circledR}$ New York State Database. Journal of Neurotrauma, 29(7), 1306-1312. http://dx.doi.org/10.1089/neu.2011.1988

Schneier, A. J., Shields, B. J., Hostetler, S. G., Xiang, H. Y., \& Smith, G. A. (2006). Incidence of Pediatric Traumatic Brain Injury and Associated Hospital Resource Utilization in the United States. Pediatrics, 118(2), 483-492. http://dx.doi.org/10.1542/peds.2005-2588

Stone, J. L., Lang, R. G., Sugar, O., \& Moody, R. A. (1981). Traumatic Subdural Hygroma. Neurosurgery, 8(5), 542-550. http://dx.doi.org/10.1227/00006123-198105000-00005

Sun, H.-L., Chang, C.-J., \& Hsieh, C.-T. (2014). Contralateral Acute Subdural Hematoma Occurring after Evacuation of Subdural Hematoma with Coexistent Contralateral Subdural Hygroma. Neurosciences (Riyadh, Saudi Arabia), 19(3), 229-232.

Tanaka, Y., \& Ohno, K. (2013). Chronic Subdural Hematoma-an up-to-Date Concept. J Med Dent Sci, 60(2), $55-61$.

Thompson, W, L., Lee, M., \& MacIntosh, R. B. (2015). Intracranial Subdural Hygroma after Le Fort I Osteotomy. Journal of Oral and Maxillofacial Surgery, 73(4), 727-731. http://dx.doi.org/10.1016/j.joms. 2014.10.023

Todorow, S., \& Happe, M. (1981). Traumatic Subdural Hygromas (author's Transl). Neurochirurgia, 24(4), 131-136.

Traumatic Epidural Haematoma of the Posterior Fossa in Childhood: 16 New Cases and a Review of the Literature. PubMed-NCBI

Van Den Berg, J. S. P., Sijbrandy, S. E., Meijer, A. H., \& Oostdijk, A. H. J. (2002). Subdural Hygroma: A Rare Complication of Spinal Anesthesia. Anesthesia \& Analgesia, 94(6), 1625-1627.

Wad, M., Pedersen, B. L., Lönn, L., \& Sillesen, H. (2013). Hygroma Following Endovascular Femoral Aneurysm Exclusion: A Case Report. International Journal of Surgery Case Reports, 4(10), 831-833. http://dx.doi.org/10.1016/j.ijscr.2013.06.013

Wittschieber, D., Karger, B., Niederstadt, T., Pfeiffer, H., \& Hahnemann, M. L. (2015). Subdural Hygromas in Abusive Head Trauma: Pathogenesis, Diagnosis, and Forensic Implications. AJNR. American Journal of Neuroradiology, 36(3), 432-439. http://dx.doi.org/10.3174/ajnr.A3989

Wu, X., Hu, J., Zhuo, L. F., Fu, C. W., Hui, G. Z., Wang, Y. H., ... Xu, G. S. (2008). Epidemiology of Traumatic Brain Injury in Eastern China, 2004: A Prospective Large Case Study. The Journal of Trauma, 64(5), 1313-1319. http://dx.doi.org/10.1097/ TA.0b013e318165c803

Zanini, M. A., Resende, L. A. D. L., Faleiros, A. T. D. S., \& Gabarra, R. C. (2008). Traumatic Subdural Hygromas: Proposed Pathogenesis Based Classification. The Journal of Trauma, 64(3), 705-713. http://dx.doi.org/10.1097/TA.0b013e3180485cfc 


\section{Copyrights}

Copyright for this article is retained by the author(s), with first publication rights granted to the journal.

This is an open-access article distributed under the terms and conditions of the Creative Commons Attribution license (http://creativecommons.org/licenses/by/3.0/). 